\title{
Growing up after childhood cancer: maturity and life satisfaction in young adulthood
}

\author{
Taylor M. Dattilo ${ }^{1}$ (1) Randal S. Olshefski ${ }^{2}$. Leena Nahata ${ }^{1,3,4} \cdot$ Jennifer A. Hansen-Moore ${ }^{5}$ Cynthia A. Gerhardt ${ }^{1,4,5}$. \\ Vicky Lehmann ${ }^{1,6}$ (B)
}

Received: 7 October 2020 / Accepted: 28 April 2021 / Published online: 7 May 2021

(c) The Author(s) 2021

\begin{abstract}
Purpose Young individuals face a variety of developmental tasks as they mature into adulthood. For survivors of childhood cancer, growing up may be more difficult due to their illness and late effects from treatment. This study is the first to quantitatively examine perceptions of maturity and how these perceptions contribute to satisfaction with life among young adult survivors of childhood cancer.

Methods Ninety survivors of childhood cancer $\left(M_{\text {age }}=29.8 ; 7-37\right.$ years post-diagnosis $)$ were recruited to complete online surveys on how mature they felt relative to peers, their perceived maturity on three domains (financial, personal, social), and life satisfaction.

Results Most survivors (62\%; $n=56)$ felt they grew up faster than their peers, and over half $(56 \% ; n=50)$ felt more mature. Perceived maturity was high on all three domains, but brain tumor survivors reported significantly lower maturity than other survivors $(d=0.76-1.11)$. All maturity domains were positively associated with life satisfaction $(r=.49-.56)$. Hierarchical linear regressions indicated that $44 \%$ of the variance in life satisfaction was explained by perceptions of growing up slower $(\beta=-1.08, p=.004)$ and marginally by greater perceived personal maturity $(\beta=0.45, p=.061)$.

Conclusions Childhood cancer can influence development, with most survivors feeling that they grew up faster and were more mature than peers. Personal maturity was related to life satisfaction, with survivors of brain tumors or those who felt they grew up slower at greatest risk for lower life satisfaction. Future research and clinical practice should consider survivors' development and maturation across the life span to promote overall well-being.
\end{abstract}

Keywords Childhood cancer $\cdot$ Life satisfaction $\cdot$ Maturity $\cdot$ Oncology $\cdot$ Survivor $\cdot$ Young adulthood

Vicky Lehmann

v.lehmann@amsterdamumc.nl

1 Center for Biobehavioral Health, The Abigail Wexner Research Institute At Nationwide Children's Hospital, Columbus, $\mathrm{OH}, \mathrm{USA}$

2 Division of Hematology/Oncology/BMT, Nationwide Children's Hospital, Columbus, OH, USA

3 Divison of Endocrinology, Nationwide Children's Hospital, Columbus, OH, USA

4 Department of Pediatrics, The Ohio State University College of Medicine, Columbus, OH, USA

5 Division of Pediatric Psychology and Neuropsychology, Nationwide Children's Hospital, Columbus, OH, USA

6 Department of Medical Psychology, Amsterdam University Medical Centers, Cancer Center Amsterdam, University of Amsterdam, Meibergdreef 9, 1105AZ Amsterdam, The Netherlands

\section{Background}

Survival rates for childhood cancer now exceed $80 \%[1,2]$. As a result, most survivors will grow up and transition into new life phases, such as emerging and young adulthood [2]. These phases are marked by significant change and growth that largely define them as the adults that they will become. Key developmental tasks during this time focus on future ambitions and goals, like choosing a career, living independently, or starting a family [3, 4]. Achievement of these socially valued milestones often builds on one another and is, therefore, an important step toward maturity and adulthood. While such transitions may be exciting, they can also be challenging, especially for childhood cancer survivors [5]. Cancer treatment itself and the emergence of late effects can disrupt physical and psychosocial development $[5,6]$. Yet, limited research has examined how cancer affects 
perceptions of maturity in young adult survivors of childhood cancer.

Qualitative research among survivors of childhood cancer indicates a "dual reality," where developmental changes can be experienced as both positive and negative [7-10]. For example, young adult survivors can experience positive emotions and have an optimistic attitude towards life after overcoming cancer, while also recognizing the continued challenges of survivorship [7]. Survivors report growing up faster and feeling more mature than peers $[8,11]$, but also note the social cost of early maturation, including the loss of childhood innocence and normalcy, missed opportunities, and feeling different/alienated from peers $[9,12,13]$. In contrast, some survivors, particularly those who had brain tumors or neurotoxic therapies, may delay or fail to achieve certain developmental milestones [14, 15]. For example, neurocognitive impairments may negatively affect educational attainment or contribute to social difficulties [16-18]. These challenges can further cascade into problems navigating social interactions, such as dating and romantic/sexual relationships [6, 19-21]. Importantly, milestones of social maturity, such as having meaningful friendships, engaging in romantic relationships, or getting married, are key indicators used by many people to rate their success and happiness in life [22]. As a result, some survivors may be at risk for diminished well-being and lower satisfaction with life in adulthood [23]. Yet, whether and to what extent different aspects of maturation play a role in survivors' overall life satisfaction remains unknown.

Some studies among adult survivors of childhood cancer reported compromised satisfaction with life [24, 25], whereas others found no differences relative to the general population [26-28]. Moreover, little is known about factors that contribute to this variability in life satisfaction. For example, potential sex differences remain largely unknown as there are mixed findings between male and female survivors [24-28]. Additionally, two studies have indicated lower life satisfaction among brain tumor survivors [23, 27]. Thus, it is important to understand how childhood cancer affects perceptions of development or maturation, and whether these perceptions contribute to life satisfaction.

Therefore, we examined associations between the perceived pace of growing up, maturity, and life satisfaction among young adult survivors of childhood cancer. It was hypothesized that most survivors report growing up faster and feeling more mature than peers, and we expected a positive association of maturity and life satisfaction. Given limited previous evidence, we also explored the effects of background factors on maturity and satisfaction with life.

\section{Methods}

\section{Study design}

Data were part of a larger study on the psychosexual development of childhood cancer survivors [21, 29]. Eligible survivors were $20-40$ years old, diagnosed between ages 5 and 18 years at a large pediatric academic hospital in the Midwest of the USA, and were $\geq 5$ years post-diagnosis. They were initially recruited in 2013-2015, resulting in 149 participants. In 2016, participating survivors were invited to complete a follow-up assessment. The Institutional Review Board (IRB 16-00426) approved all procedures.

Of the 149 survivors eligible for follow-up, 2 had died, and at least 28 had outdated contact information. Therefore, $119(80 \%)$ survivors potentially received the invitation letter, and 92 (62\%) visited the study website and participated. Written informed consent was provided online before survivors began the survey. Two survivors had incomplete data and were excluded from the presented analyses, resulting in a final sample of $N=90$ survivors. Participants were 29.82 years old ( $\mathrm{SD}=5.12$; range: $22-43$ years), had been diagnosed an average age of $11.84(S D=3.61$, range: $5-18)$, and were currently $7-37$ years $(M=17.98, \mathrm{SD}=5.63)$ postdiagnosis (see additional information in Table 1).

\section{Measures}

\section{Demographic and medical characteristics}

Participants self-reported basic demographic information online, including age, sex, relationship status, and level of education. Research staff completed medical chart reviews to collect medical characteristics, including age at diagnosis, type of diagnosis, and extent of neurotoxic treatment intensity (none, low, high [21]).

\section{Perceived maturity}

Based on the Adult Identity Profiles [30], two items were used to assess survivors' perceived growth and maturity relative to their own peers: "How fast did you grow up with regard to your same aged peers?" (response categories: "faster," "about the same," and "slower"), and "Compared to your peers, do you feel more or less mature?" (response categories: "I feel more mature than my peers," "I feel we are all quite similar," and "I feel less mature than my peers").

Due to a lack of standardized measures on self-perceived maturity, the study team created a 10-item Maturity Questionnaire (Table 2), which included a total score and three subscales: financial maturity, personal maturity, and social 
Table 1 Demographic characteristics and outcomes of perceived maturity and satisfaction with life (SwL)

\begin{tabular}{|c|c|c|c|c|c|c|}
\hline & $n(\%)$ & $\begin{array}{l}\text { Maturity } \\
M(\mathrm{SD})\end{array}$ & $\begin{array}{l}\text { Financial maturity } \\
M(\mathrm{SD})\end{array}$ & $\begin{array}{l}\text { Personal maturity } \\
M(\mathrm{SD})\end{array}$ & $\begin{array}{l}\text { Social maturity } \\
M(\mathrm{SD})\end{array}$ & $\begin{array}{l}\mathrm{SwL} \\
M(\mathrm{SD})\end{array}$ \\
\hline Total sample & $90(100 \%)$ & $4.1(0.8)$ & $4.2(0.9)$ & $4.1(0.8)$ & $4.1(0.9)$ & $5.4(1.3)$ \\
\hline \multicolumn{7}{|l|}{ Sex } \\
\hline Female & $56(62.2 \%)$ & $4.1(0.8)$ & $4.1(1.1)$ & $4.1(0.7)$ & $4.0(1.0)$ & $5.4(1.4)$ \\
\hline Male & $34(37.8 \%)$ & $4.3(1.2)$ & $4.4(0.7)$ & $4.2(0.7)$ & $4.2(0.8)$ & $5.5(1.2)$ \\
\hline \multicolumn{7}{|l|}{ Relationship status } \\
\hline Single & $24(26.7 \%)$ & $3.7(0.8)$ & $3.9(1.0)$ & $3.9(0.7)$ & $3.3(1.0)$ & $4.8(1.4)$ \\
\hline Partnered & $66(73.3 \%)$ & $4.3(0.7)$ & $4.3(0.9)$ & $4.2(0.8)$ & $4.4(0.8)$ & $5.7(1.2)$ \\
\hline \multicolumn{7}{|l|}{ Level of education } \\
\hline High & $62(68.9 \%)$ & $4.4(0.6)$ & $4.5(0.7)$ & $4.4(0.7)$ & $4.4(0.7)$ & $5.7(1.1)$ \\
\hline Low & $28(31.1 \%)$ & $3.6(0.8)$ & $3.5(1.0)$ & $3.7(0.8)$ & $3.5(1.1)$ & $4.8(1.4)$ \\
\hline \multicolumn{7}{|l|}{ Cancer diagnosis } \\
\hline Leukemia & $26(28.9 \%)$ & $4.2(0.6)$ & $4.3(0.8)$ & $4.2(0.6)$ & $4.2(0.9)$ & $5.4(1.2)$ \\
\hline Brain tumor & $23(25.6 \%)$ & $3.6(0.9)^{\mathrm{a}}$ & $3.7(1.2)$ & $3.7(0.9)^{b}$ & $3.4(1.2)^{\mathrm{a}}$ & $4.9(1.4)^{\mathrm{c}}$ \\
\hline Lymphoma & $22(24.4 \%)$ & $4.4(0.7)$ & $4.3(0.9)$ & $4.4(0.7)$ & $4.4(0.6)$ & $5.5(1.4)$ \\
\hline Other solid tumor & $19(21.1 \%)$ & $4.4(0.6)$ & $4.3(0.8)$ & $4.4(0.5)$ & $4.4(0.7)$ & $6.1(0.6)$ \\
\hline \multicolumn{7}{|l|}{ Neurotoxic treatment } \\
\hline None & $29(32.2 \%)$ & $4.3(0.7)$ & $4.3(0.9)$ & $4.3(0.7)$ & $4.3(0.8)$ & $5.8(0.9)$ \\
\hline Low dose & $22(24.4 \%)$ & $4.2(0.6)$ & $4.4(0.7)$ & $4.1(0.8)$ & $4.1(0.9)$ & $5.3(1.3)$ \\
\hline High dose & $39(43.3 \%)$ & $4.0(0.9)$ & $4.0(1.1)$ & $4.1(0.8)$ & $3.9(1.1)$ & $5.2(1.5)$ \\
\hline \multicolumn{7}{|l|}{ Age at diagnosis } \\
\hline$\leq$ age 12 & $49(54 \%)$ & $4.0(0.8)$ & $4.0(1.1)$ & $4.0(0.8)$ & $4.0(1.0)$ & $5.2(1.4)$ \\
\hline$>$ age 12 & $41(46 \%)$ & $4.3(0.7)$ & $4.4(0.8)$ & $4.2(0.7)$ & $4.3(0.8)$ & $5.7(1.1)$ \\
\hline
\end{tabular}

Significant differences are bolded

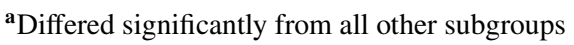

${ }^{\mathbf{b}}$ Differed significantly from lymphoma and other solid tumor survivors

${ }^{\mathbf{c}}$ Differed significantly from other solid tumor survivors

maturity. The financial maturity subscale includes three items assessing how adult/mature survivors felt about their financial independence, school/job competency, and managing their own responsibilities (e.g., bills, insurance).
The personal maturity subscale includes four items: emotional stability, autonomy, managing their own health, and ambitions/goals for the future. The social maturity subscale includes three items: assessing friendships/social
Table 2 Items of the Maturity Questionnaire as ranked by survivors

\begin{tabular}{llllll}
\hline & & $M(\mathrm{SD})$ & Rank by $M$ & $\begin{array}{l}\text { Endorsed "very } \\
\text { mature" \% }\end{array}$ & Rank by \% \\
\hline F & School/job competence & $4.3(0.9)$ & 1 & $55.6 \%$ & 1 \\
P & Managing own health & $4.3(0.8)$ & 2 & $45.6 \%$ & 6 \\
F & Managing own responsibilities & $4.2(1.0)$ & 3 & $52.2 \%$ & 2 \\
& $\quad$ (e.g., bills, insurances) & & & $47.8 \%$ & 5 \\
P & Autonomy & $4.2(0.9)$ & 4 & $44.4 \%$ & 7 \\
S & Friendships/social relationships & $4.2(1.0)$ & 5 & $44.4 \%$ & 7 \\
P & Ambitions/goals for the future & $4.1(1.0)$ & 6 & $50.0 \%$ & 3 \\
S & Dating/romantic relationships & $4.1(1.2)$ & 7 & $44.4 \%$ & 7 \\
S & Family planning & $4.0(1.1)$ & 8 & $34.4 \%$ & 8 \\
P & Emotional stability & $4.0(1.0)$ & 9 & $49.9 \%$ & 4 \\
F & Financial independence & $3.9(1.3)$ & 10 & \\
\hline
\end{tabular}

$F$ Financial maturity, $S$ Social maturity, $P$ Personal maturity 
relationships, dating/romantic relationships, and family planning. All items were answered on a 5-point scale: "not at all"- "very adult/mature." Mean scores were calculated with higher scores indicating greater perceived maturity. Internal consistency was excellent for the total score $(\alpha=.90)$ and very good for the three subscales: financial maturity ( $\alpha=.83$ ), personal maturity ( $\alpha=.81$ ), and social maturity $(\alpha=.83)$.

\section{Satisfaction with life}

The Satisfaction with Life Scale (SWLS [31]) is a widely used 5-item questionnaire to assess the degree to which participants are satisfied with life. Items are rated on a 7-point scale ("strongly disagree"- "strongly agree") and include statements such as "In most ways my life is close to ideal." Higher scores indicate greater satisfaction and internal consistency was excellent $(\alpha=.91)$.

\section{Statistical analyses}

Data were analyzed using SPSS Statistics by IBM, version 25.0. Descriptive statistics will be used to summarize survey responses. Differences in maturity based on demographic and medical factors will be examined using $t$-tests, oneway ANOVAs, or Pearson's correlation, depending on the variable: sex, age, relationship status (partnered vs. single), educational level (low vs. high), age at diagnosis (childhood vs. adolescence), type of diagnosis, and extent of neurotoxic treatment regimens (no, low, high [21]). To test the relative contribution of demographic and medical factors, only those significant at $p<0.05$ will be included in a linear regression analysis on total maturity scores.

Differences in life satisfaction by demographic and medical factors will similarly be examined as indicated above (i.e., using $t$-tests, one-way ANOVAs, or Pearson's correlation, depending on the variable). Associations between both primary outcomes (i.e., maturity and life satisfaction) will be tested using Pearson's correlations. Finally, a hierarchical linear regression will test the relative contribution of significant demographic and medical factors and maturity on life satisfaction. Thus, demographic and medical factors that will be identified as significantly related to life satisfaction in univariate analyses $(p<0.05)$ are entered in step 1, followed by the three maturity subscales in step 2 .

\section{Results}

\section{Maturity}

Sixty-two percent of survivors $(n=56)$ felt they grew up faster than their peers, while only $12 \%(n=11)$ felt they grew up slower. Fifty-six percent $(n=50)$ felt more mature than their peers, while $11 \%(n=10)$ felt less mature. Of all 10 items included in the Maturity Questionnaire, the highest mean scores were reported for school/job competency and managing one's health, whereas lowest scores were reported for emotional stability and financial independence (Table 2). However, when examining these items by how many times survivors endorsed the highest possible response category ("very mature"), a slightly different distribution appeared. Both distributions showed high perceived maturity on school/job competency and managing one's own responsibilities, but the least frequently endorsed items included family planning, ambitions/goals, and friendships/social relationships (see Table 2 for direct comparisons).

The total score for perceived maturity was high $(M=4.1)$, given a potential range of $1-5$, and similar across subscales: financial $(M=4.2)$, personal $(M=4.1)$, and social maturity $(M=4.0$, Table 2). Testing whether demographic and medical factors were related to maturity showed that partnered survivors perceived themselves as more mature than single survivors ( $M=4.3$ vs. 3.7$), t(88)=-3.13, p=0.002$; $d=0.72$, particularly for social maturity ( $M=4.4$ vs. 3.3$)$, $t(88)=-4.66, p<.001, d=1.18$ (Table 1). Moreover, older age at study participation was weakly associated with greater maturity, $r=0.22, p=0.038$. Importantly, partnered survivors were older than singles $(M=28.0$ vs. 30.5$)$, $t(88)=-2.12, p=0.037$, but testing maturity differences among partnered and single survivors, while controlling for age, did not change the findings reported above. Finally, higher educated survivors perceived themselves as more mature than those with a lower education $(M=4.4$ vs. 3.6), $t(88)=5.45, p<0.001 ; d=1.18$, while sex was not related to perceived maturity.

Regarding medical factors, total maturity scores differed by the type of diagnosis, $F(3,86)=5.45, p=0.002$. Brain tumor survivors $(M=3.6)$ reported significantly lower maturity scores than survivors of leukemia $(M=4.2$, $d=0.76)$, lymphoma $(M=4.4, d=0.90)$, and other solid tumors $(M=4.4, d=1.11)$. At the subscale level, it appeared that this difference was driven by social maturity, where brain tumor survivors reported the lowest scores relative to all other diagnostic groups, $F(3,86)=6.26, p=0.001$, $d=0.25-0.28$ (Table 1). Brain tumor survivors also reported significantly lower personal maturity $(M=3.68)$ than survivors of lymphoma $(M=4.4)$ and other solid tumors $(M=4.4), F(3,86)=4.70, p=0.004, d=0.83-0.99$ (Table 1$)$. There was a borderline significant difference regarding age at diagnosis, $F(1,88)=3.92, p=0.051$. Specifically, those diagnosed during childhood ( $\leq$ age 12 ) reported lower maturity scores compared to survivors diagnosed during adolescence ( $M=4.0$ vs. $4.3, d=0.42$ ). Finally, neurotoxic treatment regimens appeared unrelated to perceived maturity (Table 1). 
The overall regression model on maturity was significant, $F(5,84)=10.77, p<0.001$, explaining $39.1 \%$ of the total variance. A brain tumor diagnosis $(\beta=-0.30, p=0.002)$ and lower education $(\beta=-0.46, p<0.001)$ were associated with lower perceived maturity (Table 3 ).

\section{Satisfaction with life}

Life satisfaction was high $(M=5.4)$ on a scale from $1-7$. Partnered survivors were more satisfied with life than single survivors $(M=5.7$ vs. 4.8$), t(88)=-2.94, p=0.004$, $d=0.66$, and those with higher education were more satisfied than those with a lower education ( $M=5.7$ vs. 4.8$)$, $t(88)=3.35, p=0.001, d=0.73$. Moreover, satisfaction differed by type of diagnosis, $F(3,85)=3.35, p=0.023$. Specifically, brain tumor survivors were significantly less satisfied with life $(M=4.9)$ than survivors of other solid tumors $(M=6.1, d=1.12)$. Sex, age at study, age at diagnosis, and neurotoxic treatment regimens were not associated with life satisfaction (Table 1).

Although subgroups were small, survivors' pace of growing up appeared to matter for satisfaction with life. Survivors who indicated having grown up slower than peers $(n=11)$ were significantly less satisfied with life $(M=3.9)$ than those who reportedly grew up faster $(n=56 ; M=5.7, d=1.55)$ and those who felt similar to peers $(n=23, M=5.5, d=1.32$; $F(2,87)=11.72, p<0.001)$, which are considered very large differences. Most of these survivors were female (72.7\%; $n=8 / 11)$ and/or diagnosed during childhood (63.6\%; $n=7 / 11$ ), but subgroups were too small to test differences statistically.

Bivariate correlations between satisfaction with life and the three maturity subscales showed moderate associations. The strongest correlation was between life satisfaction and personal maturity $(r=0.56, p<0.001)$, followed by financial and social maturity $(r=0.49, p<0.001$ each).

Based on differences identified above, the final hierarchical linear regression included relationship status, education, type of diagnosis, and perceptions of pace of growing up in step 1 , before adding the three maturity subscales in step 2 .

Table 3 Linear regression on total maturity scores

\begin{tabular}{llrc}
\hline Variable & \multicolumn{2}{l}{ Maturity } \\
\cline { 2 - 4 } & $B(\mathrm{SE})$ & \multicolumn{1}{l}{$\beta$} & $p$-value \\
\hline Relationship status: partnered $^{\mathrm{a}}$ & $0.13(0.17)$ & 0.07 & .454 \\
Age at study participation & $-0.01(0.01)$ & -0.03 & .746 \\
Education: lower $^{\mathrm{b}}$ & $-0.75(0.15)$ & -0.46 & $\mathbf{. 0 0 0}$ \\
Diagnosis: brain tumor $^{\mathrm{c}}$ & $-0.53(0.17)$ & -0.30 & $\mathbf{. 0 0 2}$ \\
Age at diagnosis: adolescence $^{\mathrm{d}}$ & $0.19(0.14)$ & 0.12 & .173 \\
\hline
\end{tabular}

$R^{2}=.39, F(5,84)=10.77, p<.001$; reference categories: ${ }^{\mathrm{a}} \mathrm{vs}$. single; ${ }^{\mathrm{b}}$ vs. high; ${ }^{\mathrm{c}}$ vs. non-CNS; ${ }^{\mathrm{d}}$ vs. childhood
The overall model in step 1 was significant, $F(4,85)=10.59$, $p<0.001$, explaining $33.2 \%$ of the total variance. Perceptions of growing up slower $(\beta=-0.39, p<0.001)$ and lower education $(\beta=-0.26, p=0.005)$ were associated with lower life satisfaction (Table 4). Adding the maturity subscales in step 2 significantly improved the model and added another $10.4 \%$ of explained variance, $F(7,82)=9.09, p<0.001$, $R^{2}=0.44$. Interestingly, growing up slower remained significant $(\beta=-0.27, p=0.004)$, whereas education did not $(\beta=-0.07, p=0.454)$. Personal maturity approached significance $(\beta=0.26, p=0.061)$ suggesting a positive association with life satisfaction beyond demographic and medical factors (Table 4).

\section{Discussion}

To our knowledge, this is the first study to quantitatively assess different aspects of perceived maturity and examine associations with life satisfaction among young adult survivors of childhood cancer. Results indicate that childhood cancer can have a substantial impact on perceived development, with most survivors reporting they grew up faster than their peers and they felt rather mature. Perceived maturity, and personal maturity in particular, was linked to higher life satisfaction, but certain demographic and medical factors can play a role. Our findings are consistent with studies demonstrating positive growth (i.e., personal maturation/development) as well as high levels of life satisfaction among most, but not all, survivors [7, 8].

Many survivors in this study felt they grew up faster than their peers. Based on previous research, some survivors

Table 4 Hierarchal linear regression on satisfaction with life

\begin{tabular}{|c|c|c|c|}
\hline \multirow[t]{2}{*}{ Variable } & \multicolumn{3}{|c|}{ Life satisfaction } \\
\hline & $B(\mathrm{SE})$ & $\beta$ & $p$-value \\
\hline \multicolumn{4}{|c|}{ Step 1: $R^{2}=.33, F(4,85)=10.59, p<.001$} \\
\hline Relationship status: partnered ${ }^{\mathrm{a}}$ & $0.24(0.30)$ & 0.08 & .420 \\
\hline Education: lower ${ }^{\mathrm{b}}$ & $-0.72(0.25)$ & -0.26 & .005 \\
\hline Diagnosis: brain tumor ${ }^{\mathrm{c}}$ & $-0.48(0.29)$ & -0.16 & .106 \\
\hline Growing up slower $^{\mathrm{d}}$ & $-1.54(0.36)$ & -0.39 & .000 \\
\hline \multicolumn{4}{|c|}{ Step 2: $R^{2}=.44, F(7,82)=9.09, p<.001$} \\
\hline Relationship status: partnered ${ }^{\mathrm{a}}$ & $0.35(0.32)$ & 0.12 & .272 \\
\hline Education: lower ${ }^{\mathrm{b}}$ & $-0.21(0.27)$ & -0.07 & .454 \\
\hline Diagnosis: brain tumor ${ }^{\mathrm{c}}$ & $-0.08(0.30)$ & -0.03 & .787 \\
\hline Growing up slower $^{\mathrm{d}}$ & $-1.08(0.36)$ & -0.27 & .004 \\
\hline Financial maturity & $0.25(0.17)$ & 0.18 & .146 \\
\hline Social maturity & $0.03(0.19)$ & 0.02 & .880 \\
\hline Personal maturity & $0.45(0.24)$ & 0.26 & .061 \\
\hline
\end{tabular}

$\Delta R^{2}=.10, \Delta F(3,82)=5.07, p=.003$; reference categories: ${ }^{\mathrm{a}} \mathrm{vs}$. single;

bs. high; ${ }^{\mathrm{c}}$ vs. non-CNS; ${ }^{\mathrm{d}} \mathrm{vs}$. similar/faster 
may see this as a positive difference (e.g., feeling positive about being more mature), while other survivors may experience this negatively (e.g., feeling alienated or not fitting in with peers [7, 9, 13, 32]). Survivors felt most mature about aspects related to financial (i.e., school/job performance, managing bills/insurances) and personal maturity (i.e., managing own health, autonomy), whereas survivors felt least mature about aspects of social maturity (i.e., dating, family planning). Within the financial maturity subscale, survivors rated school job performance highest, although they perceived their financial independence as lowest. These findings are similar to reports from survivors of adolescent and young adult cancer (AYA), who also experience challenges regarding employment and financial stability [33]. Yet, our findings contrast reports of AYA survivors who struggle with education [33]. One explanation may be that treatment coincides with such developmental tasks (pursuing higher education or starting a career) among AYA cancer patients, whereas treatment is typically completed for survivors of childhood cancer before these developmental milestones become salient.

Survivors of brain tumors perceived themselves as least mature and satisfied with life relative to other survivors. This is consistent with research which highlighted diminished social functioning among survivors of pediatric brain tumors [34], as well as psychosocial difficulties across the lifespan $[5,6,35]$, potentially resulting in diminished independence. Parents may also become more protective and potentially hamper survivors' autonomy because of concerns about cognitive functioning, developmental delays, and/or psychosocial difficulties [36, 37]. In contrast, neurotoxic treatment intensity was not related to perceived maturity. The specific mechanisms that may lead to perceptions of decreased maturity/independence among brain tumor survivors but not among those who received high levels of neurotoxic treatments remain unclear.

Partnered survivors perceived themselves as more mature than single survivors, even when controlling for age. This is not surprising given that engaging in more serious relationships/marriage is one developmental task in young adulthood that is often used as an indicator of maturity. At the same time, having a partner may also increase opportunities to accomplish other indicators of maturity, such as financial stability due to a shared income, buying a house, or family planning. Thus, relationship status is intertwined with other aspects of maturity, along with the simple progression of aging, and should be considered when discussing development with survivors. Providers may also address potential difficulties with dating and sexual health if it appears to hamper survivors' overall quality of life [6, 19-21].

Interestingly, no sex differences in maturity and satisfaction with life were identified in this study. This is in line with previous satisfaction research [24-28, 38], but it is also surprising given that sex differences in quality of life are commonly found. It is also possible that interactions may exist, but our sample size and limited power precluded testing these potential effects. For example, some research has indicated that male brain tumor survivors may have more difficulties with developmental milestones than females [39]. Thus, additional research is needed to further contextualize and measure aspects of quality of life vs. life satisfaction, as well as to examine interactions of demographic and medical factors.

Survivors' perceptions of growing up slower than peers and lower education were associated with lower life satisfaction. Yet, the number of survivors falling into either subgroup was small, which is promising. Our findings highlight overall high satisfaction with life, which is consistent with the research of positive growth following cancer, aiding in a successful transition to adulthood and attainment of developmental milestones [40, 41]. This finding also corroborates previous research in congenital heart disease/heart transplant survivors that found maturity is associated with increased quality of life $[42,43]$. This suggests that emotional and personal stability/growth, as well as autonomy could positively contribute to feelings of responsibility and control over life, and therefore reinforce survivors' life satisfaction.

\section{Study limitations}

This study presents novel insights, but some limitations should be considered. First, recruitment of a healthy control group would facilitate direct comparisons regarding development and maturity. Second, although our sample was sizeable and analyses had acceptable power, more detailed analyses were not possible. Interactions between certain demographic and medical factors should be tested (e.g., male vs. female brain tumor survivors vs. others), as well as effects among more refined groups regarding age at diagnosis (e.g., younger vs. older adolescents). Third, perceptions of maturity were self-reported and may differ from how others perceive survivors' maturity. Yet, such selfperceptions may be more salient indicators of satisfaction than the attainment of normative developmental milestones in itself, which needs further investigation. Fourth, the family of origin might play a crucial role in the maturation of survivors and reaching their autonomy, but this was outside the scope of this study. Finally, and as indicated above, this study used cross-sectional data, limiting our ability to infer causal relationships.

\section{Clinical implications}

To maximize satisfaction with life throughout survivorship, healthcare providers should regard maturation and development as a process across the life span and support 
childhood cancer survivors in accomplishing developmental tasks in each life phase. Specific attention may be needed for survivors who feel their development was slowed by their cancer experience, along with survivors of brain tumors. Healthcare providers are advised to screen survivors for potential delays or burdens related to maturity and development, for which the items of the Maturity Scale may be useful. Moreover, psychosocial providers should counsel survivors regarding dating/romantic relationships, financial independence, family planning, and emotional stability in a developmentally appropriate way. A specific focus on promoting positive gains of personal maturity (emotional stability, goal setting) may be warranted, as this could increase overall satisfaction with life among all survivors of childhood cancer.

Funding Parts of this study were funded by a grant from the Research Institute at Nationwide Children's Hospital (Lehmann) and a grant from the National Center for Advancing Translational Sciences (NCATS;UL1TR002733).

Data availability De-identified data supporting the findings of this study are available from the corresponding author upon request.

Code availability Not applicable.

\section{Declarations}

Ethics approval Our Institutional Review Board (IRB16-00426) approved all procedures, which are also in accordance with the Declaration of Helsinki.

Consent to participate and for publication All participant provide written informed consent online before starting the survey. Thereby, they also acknowledged the usage of data for scientific publications.

Conflict of interest The authors declare no competing interests.

Disclaimer The content of this manuscript is the responsibility of the authors and does not necessarily represent the official views of the NCATS or National Institutes of Health.

Open Access This article is licensed under a Creative Commons Attribution 4.0 International License, which permits use, sharing, adaptation, distribution and reproduction in any medium or format, as long as you give appropriate credit to the original author(s) and the source, provide a link to the Creative Commons licence, and indicate if changes were made. The images or other third party material in this article are included in the article's Creative Commons licence, unless indicated otherwise in a credit line to the material. If material is not included in the article's Creative Commons licence and your intended use is not permitted by statutory regulation or exceeds the permitted use, you will need to obtain permission directly from the copyright holder. To view a copy of this licence, visit http://creativecommons.org/licenses/by/4.0/.

\section{References}

1. Ward E, DeSantis C, Robbins A, Kohler B, Jemal A (2014) Childhood and adolescent cancer statistics, 2014. CA Cancer J Clin 64(2):83-103

2. Erdmann F, Frederiksen LE, Bonaventure A, Mader L, Hasle H, Robison LL, Winther JF (2020) Childhood cancer: survival, treatment modalities, late effects and improvements over time. Cancer Epidemiol 101733. https://doi.org/10.1016/j.canep.2020.101733

3. Arnett JJ (2000) Emerging adulthood: a theory of development from the late teens through the twenties. Am Psychol 55(5):469

4. Arnett JJ, Tanner JL (2006) Emerging adults in America: coming of age in the 21 st century. Citeseer,

5. Lewis P, Jordens CF, Mooney-Somers J, Smith K, Kerridge I (2013) Growing up with cancer: accommodating the effects of cancer into young people's social lives. J Pediatr Oncol Nurs 30(6):311-319

6. Stam H, Grootenhuis M, Last B (2005) The course of life of survivors of childhood cancer. Psycho-Oncol J Psychol Soc Behav Dimensions Cancer 14(3):227-238

7. Lehmann V, Grönqvist H, Engvall G, Ander M, Tuinman MA, Hagedoorn M, Sanderman R, Mattsson E, von Essen L (2014) Negative and positive consequences of adolescent cancer 10 years after diagnosis: an interview-based longitudinal study in Sweden. Psychooncology 23(11):1229-1235

8. Zebrack BJ, Stuber ML, Meeske KA, Phipps S, Krull KR, Liu Q, Yasui Y, Parry C, Hamilton R, Robison LL (2012) Perceived positive impact of cancer among long-term survivors of childhood cancer: a report from the childhood cancer survivor study. Psychooncology 21(6):630-639

9. Nightingale CL, Quinn GP, Shenkman EA, Curbow BA, Zebrack BJ, Krull KR, Huang I-C (2011) Health-related quality of life of young adult survivors of childhood cancer: a review of qualitative studies. J Adolesc Young Adult Oncol 1(3):124-132

10. Cantrell MA (2011) A narrative review summarizing the state of the evidence on the health-related quality of life among childhood cancer survivors. J Pediatr Oncol Nurs 28(2):75-82

11. Phipps S, Long AM, Ogden J (2007) Benefit Finding Scale for Children: preliminary findings from a childhood cancer population. J Pediatr Psychol 32(10):1264-1271. https://doi.org/10.1093/jpepsy/js1052

12. Belpame N, Kars MC, Deslypere E, Rober P, Van Hecke A, Verhaeghe S (2019) Living as a cancer survivor: a qualitative study on the experiences of Belgian adolescents and young adults (AYAs) after childhood cancer. J Pediatr Nurs 49:e29-e35. https://doi.org/ 10.1016/j.pedn.2019.07.015

13. Anthony SJ, Robertson T, Selkirk E, Dix D, Klaassen RJ, Sung L, Klassen AF (2019) The social impact of early psychological maturity in adolescents with cancer. Psychooncology 28(3):586-592. https://doi.org/10.1002/pon.4982

14. Servitzoglou M, Papadatou D, Tsiantis I, Vasilatou-Kosmidis H (2008) Psychosocial functioning of young adolescent and adult survivors of childhood cancer. Support Care Cancer 16(1):29-36

15. Sheinfeld Gorin $S$, McAuliffe $P$ (2008) Implications of childhood cancer survivors in the classroom and the school. Health Educ 109(1):25-48

16. Mulhern RK, Merchant TE, Gajjar A, Reddick WE, Kun LE (2004) Late neurocognitive sequelae in survivors of brain tumours in childhood. Lancet Oncol 5(7):399-408

17. Annett RD, Patel SK, Phipps S (2015) Monitoring and assessment of neuropsychological outcomes as a standard of care in pediatric oncology. Pediatr Blood Cancer 62(S5):S460-S513 
18. Yeates KO, Bigler ED, Dennis M, Gerhardt CA, Rubin KH, Stancin T, Taylor HG, Vannatta K (2007) Social outcomes in childhood brain disorder: a heuristic integration of social neuroscience and developmental psychology. Psychol Bull 133(3):535

19. Thompson AL, Long KA, Marsland AL (2013) Impact of childhood cancer on emerging adult survivors' romantic relationships: a qualitative account. J Sex Med 10:65-73

20. Gerhardt CA, Vannatta K, Valerius KS, Correll J, Noll RB (2007) Social and romantic outcomes in emerging adulthood among survivors of childhood cancer. J Adolesc Health 40(5):462. e469-462. e415

21. Lehmann V, Tuinman MA, Keim MC, Winning AM, Olshefski RS, Bajwa RP, Hagedoorn M, Gerhardt CA (2017) Psychosexual development and satisfaction in long-term survivors of childhood cancer: neurotoxic treatment intensity as a risk indicator. Cancer 123(10):1869-1876

22. Arnett JJ (2014) Emerging adulthood: the winding road from the late teens through the twenties. Oxford University Press, USA

23. Zeltzer LK, Recklitis C, Buchbinder D, Zebrack B, Casillas J, Tsao JC, Lu Q, Krull K (2009) Psychological status in childhood cancer survivors: a report from the Childhood Cancer Survivor Study. J Clin Oncol 27(14):2396

24. Seitz DC, Hagmann D, Besier T, Dieluweit U, Debatin K-M, Grabow D, Kaatsch P, Henrich G, Goldbeck L (2011) Life satisfaction in adult survivors of cancer during adolescence: what contributes to the latter satisfaction with life? Qual Life Res 20(2):225-236

25. Zeltzer LK, Lu Q, Leisenring W, Tsao JC, Recklitis C, Armstrong G, Mertens AC, Robison LL, Ness KK (2008) Psychosocial outcomes and health-related quality of life in adult childhood cancer survivors: a report from the childhood cancer survivor study. Cancer Epidemiol Prev Biomarkers 17(2):435-446

26. Uderzo C, Corti P, Pappalettera M, Baldini V, Lucchini G, Meani D, Rovelli A (2012) Life satisfaction in young adults 10 or more years after hematopoietic stem cell transplantation for childhood malignant and nonmalignant diseases does not show significant impairment compared with healthy controls: a case-matched study. Biol Blood Marrow Transplant 18(11):1759-1764

27. Maunsell E, Pogany L, Barrera M, Shaw AK, Speechley KN (2006) Quality of life among long-term adolescent and adult survivors of childhood cancer. J Clin Oncol 24(16):2527-2535

28. Schwartz L, Drotar D (2006) Posttraumatic stress and related impairment in survivors of childhood cancer in early adulthood compared to healthy peers. J Pediatr Psychol 31(4):356-366

29. Lehmann V, Tuinman MA, Keim MC, Hagedoorn M, Gerhardt CA (2018) Am I a 6 or a 10? Mate value among young adult survivors of childhood cancer and healthy peers. J Adolesc Young Adult Oncol 7(1):72-78

30. Benson JE, Elder GH Jr (2011) Young adult identities and their pathways: a developmental and life course model. Dev Psychol 47(6): 1646

31. Diener E, Emmons RA, Larsen RJ, Griffin S (1985) The Satisfaction with Life Scale. J Pers Assess 49(1):71-75
32. Thompson AL, Long KA, Marsland AL (2013) Impact of childhood cancer on emerging adult survivors' romantic relationships: a qualitative account. J Sex Med 10(S1):65-73. https://doi.org/10. 1111/j.1743-6109.2012.02950.x

33. Warner EL, Kent EE, Trevino KM, Parsons HM, Zebrack BJ, Kirchhoff AC (2016) Social well-being among adolescents and young adults with cancer: a systematic review. Cancer 122(7):1029-1037

34. Zebrack BJ, Gurney JG, Oeffinger K, Whitton J, Packer RJ, Mertens A, Turk N, Castleberry R, Dreyer Z, Robison LL (2004) Psychological outcomes in long-term survivors of childhood brain cancer: a report from the childhood cancer survivor study. J Clin Oncol 22(6):999-1006

35. Vannatta K, Gerhardt CA, Wells RJ, Noll RB (2007) Intensity of CNS treatment for pediatric cancer: prediction of social outcomes in survivors. Pediatr Blood Cancer 49(5):716-722

36. Hocking MC, Hobbie WL, Deatrick JA, Lucas MS, Szabo MM, Volpe EM, Barakat LP (2011) Neurocognitive and family functioning and quality of life among young adult survivors of childhood brain tumors. Clin Neuropsychol 25(6):942-962

37. Carpentieri SC, Meyer EA, Delaney BL, Victoria ML, Gannon BK, Doyle JM, Kieran MW (2003) Psychosocial and behavioral functioning among pediatric brain tumor survivors. J Neurooncol 63(3):279-287

38. Ward-Smith P, Hamlin J, Bartholomew J, Stegenga K (2007) Quality of life among adolescents with cancer. J Pediatr Oncol Nurs 24(3):166-171

39. Willard VW (2018) Social skills interventions for survivors of pediatric brain tumors: a review and reformulation. Pediatr Blood Cancer 65(12):e27434. https://doi.org/10.1002/pbc.27434

40. Kim Y (2017) Exploration of life experiences of positive growth in long-term childhood cancer survivors. Eur J Oncol Nurs 30:60-66

41. Waldboth V, Patch C, Mahrer-Imhof R, Metcalfe A (2016) Living a normal life in an extraordinary way: a systematic review investigating experiences of families of young people's transition into adulthood when affected by a genetic and chronic childhood condition. Int J Nurs Stud 62:44-59. https://doi.org/10.1016/j.jinur stu.2016.07.007

42. Hörnsten $\AA$, Norberg A, Lundman B (2002) Psychosocial maturity among people with diabetes mellitus. J Clin Nurs 11(6):777-784. https://doi.org/10.1046/j.1365-2702.2002.00689.x

43. Mackie AS, Rempel GR, Islam S, Rankin K, McCurdy C, Vonder Muhll I, Magill-Evans J, Nicholas D, Kovacs AH (2016) Psychosocial maturity, autonomy, and transition readiness among young adults with congenital heart disease or a heart transplant. Congenit Heart Dis 11(2):136-143. https://doi.org/10.1111/chd.12300

Publisher's note Springer Nature remains neutral with regard to jurisdictional claims in published maps and institutional affiliations. 